
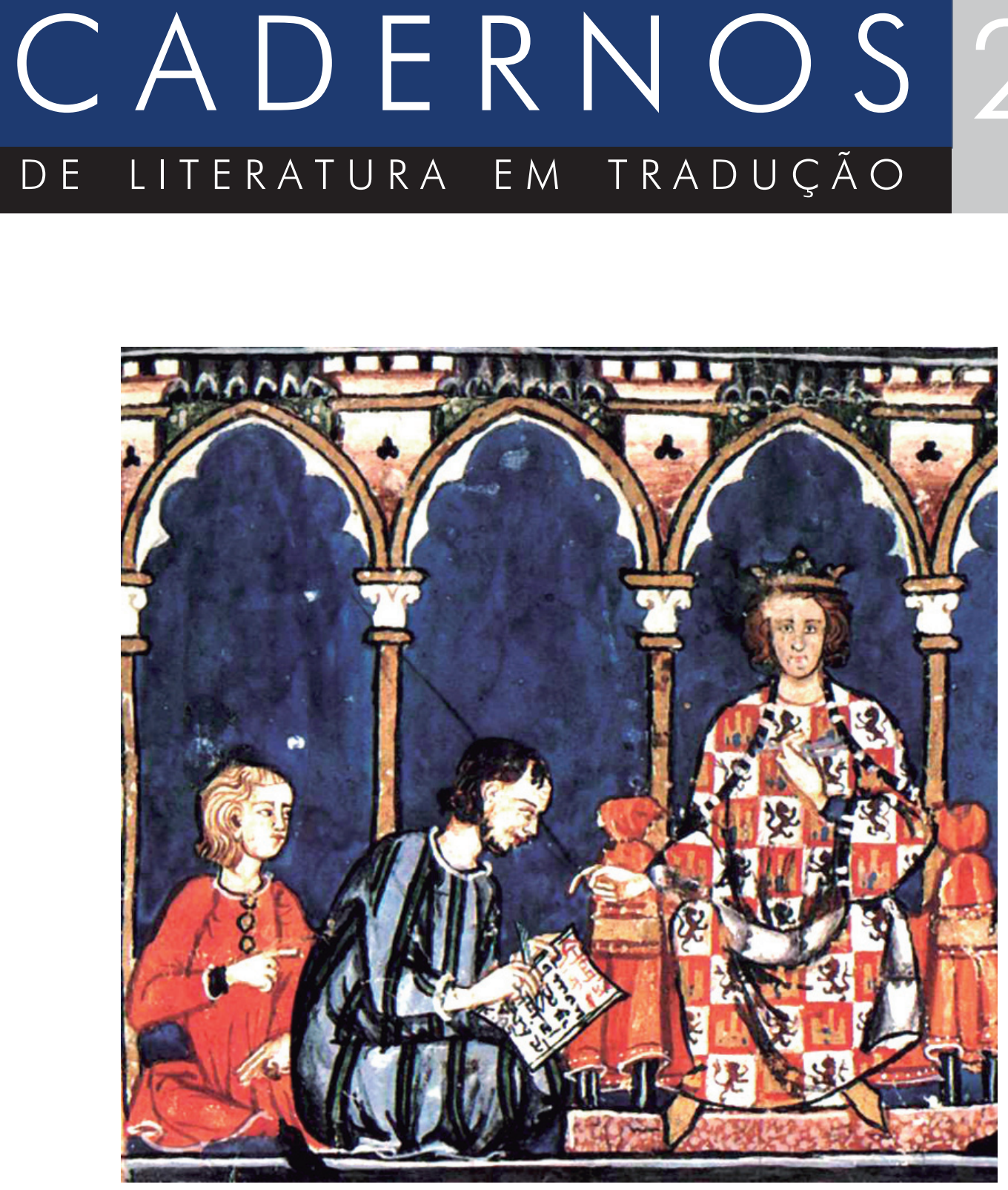

Tradutores da chamada Escola de Toledo com Afonso $X$ de Castela 


\title{
A Escola de Tradutores de Toledo: a oralidade da escrita
}

\author{
Francisco César Manhães Monteiro' ${ }^{1}$
}

\begin{abstract}
Resumo: Este artigo se volta para a análise da chamada Escola de Tradutores de Toledo, surgida na época da Primeira Cruzada, e se propõe a questionar e reformular o que se sabe sobre os seus métodos, personagens, tradutores e época, sobretudo a questão do papel da oralidade na criação, controle e eventual censura das traduções produzidas por intérpretes e tradutores hebreus, muçulmanos, convertidos e cristãos, hispânicos e francos; também, o que isso ainda afeta e pode contribuir para a prática, história e teoria da tradução.
\end{abstract}

Palavras-chave: Escola de Tradutores de Toledo; História da Tradução; Oralidade da escrita.

Resumen: Este artículo se centra en el análisis de la llamada Escuela de Traductores de Toledo, surgida en la época de la Primera Cruzada, y se propone a cuestionar y reformular lo que se sabe sobre sus métodos, personajes, traductores y tiempo. Sobre todo, la cuestión del papel de la oralidad en la creación, control y eventual censura de las traducciones producidas por intérpretes y traductores hebreos, musulmanes, conversos y cristianos, hispanos y franceses. Además, en qué dicha Escuela todavía afecta y puede contribuir a la práctica, la historia y la teoría de la traducción.

Palabras-1lave: Escuela de Traductores de Toledo; Historia de la Traducción. Oralidad de la escritura

\section{Introdução}

Contou da academia, da qual era o cabeça. Certamente, seu modesto instituto não se podia comparar com outros semelhantes entre os muçulmanos,

1 Doutor em Literaturas Neolatinas/UFRJ 
mas, de todo modo, a sabedoria dos árabes e dos pagãos da Antiguidade era transmitida ao Ocidente. "Não creia, ó Musa", esclareceu com afã, "que eu seja tacanho, mandei até mesmo traduzir o Alcorão para o latim, e alguns infiéis também trabalham na minha academia, tanto judeus como muçulmanos. Com sua permissão, trarei algum dos meus discípulos, para desfrutar da honra de uma conversa convosco" (FEUCHTWANGER, 1983, p. 91, tradução nossa) ${ }^{2}$.

Em 1955, o romancista judeu-alemão Lion Feuchtwanger (1884-1958) escreveu o romance Die Jüdin von Toledo (Feuchtwanger, 1983) em que narrava a história dos amores entre a judia Raquel de Toledo, conhecida como "La Fermosa", com o rei Alfonso VIII. O romance histórico baseia-se na Crónica General (1270) composta pelo rei e historiador Alfonso X, o Sábio. A história de Raquel também rendeu uma peça de Lope de Vega, chamada justamente La judia de Toledo. O antecessor de todos os anteriormente citados, Alfonso VII, havia reinado justamente durante o período de auge da primeira etapa da chamada Escola; foi também o primeiro rei espanhol da Casa de Borgonha, uma dinastia de origem francesa. Alfonso X, que patrocinou a segunda etapa da Escola, foi seu bisneto.

Feuchtwanger tinha escapado do nazismo na Europa e enfrentava a perseguição do macarthismo nos Estados Unidos no momento da publicação do romance mencionado. Sintomaticamente, a sua ficção da Espanha medieval é a idealização de um suposto momento em que a convivência entre povos, línguas e civilizações foi possível ou, pelo menos, tentada. A tradução ou esforço de comunicação entre culturas é quase uma personagem no romance, que proporciona visões das diferenças de concepções dos protagonistas. Na obra, a própria Akademie ou Escola de tradutores é mencionada.

Assim como Raquel, a Judia de Toledo, de Feuchtwanger e de Lope de Vega, a Escola de tradutores de Toledo é uma figura de ficção baseada em fatos reais. Do mesmo modo, a Escola de Toledo é um ente criado para encarnar idealizações e conceitos, às vezes conflitantes. Para entender o que foi, e não foi, na realidade é preciso escavar sob muitas camadas de ficções e fixações. Porém, vale a pena

2 Er erzählte ihm von der Akademie, deren Leiter er war. Gewiß könne sich dieses sein bescheidenes Institut nicht vergleichen mit ähnlichen der Moslems, aber es werde immerhin von hier aus Weisheit der Araber sowohl wie der heidnischen Alten dem Abendlande vermittelt. "Glaube ja nicht, o weiser Musa", erklärte er eifrig, "daß ich engherzig sei. Ich habe sogar den Koran ins Lateinische übersetzen lassen. Auch arbeiten an meiner Akademie manche Ungläubige, Juden wie Moslems. Wenn du es erlaubst, dann bringe ich dir einmal den einen oder ändern meiner Schüler, daß er der Ehre eines Gespräches mit dir teilhaftig werde." 
pelo papel que exerceu, seja qual tenha sido, na história do contato linguístico e civilizacional entre Ocidente e Oriente e na própria teoria e prática da tradução.

Porém, mais certo ainda é que a Escola de Tradutores designa algo relevante que parte e vai além de uma realidade histórica, tendo se tornado um conceito, mesmo que contraditório e instável.

J. C. Santoyo dedica um ensaio às lacunas e erros da historiografia da tradução e dá o episódio da "escola" toledana como exemplo de lapsos recorrentes, erros factuais e de interpretação. Entre as obras de referência que cita há menções a uma tradução do Alcorão falsamente atribuída ao abade de Cluny, Pierre de Montboissier ou Pedro o Venerável, ou à presença do bispo Ulfila, na Península Ibérica, confundindo visigodos e ostrogodos, além de outras confusões de lugares e épocas (SANTOYO, 2006).

No nosso caso, tratando-se de um fenômeno complexo, as perguntas não são simples e as respostas não são fáceis nem óbvias. Hsia e Burke (2009, p. 17) ${ }^{3}$, sugerem destrinchar essas "culturas da tradução" a partir de respostas provisórias para seis grandes perguntas: "Quem traduz? Com que intenção? O quê? Para quem? De que maneira? Com que consequências?” Começaremos pela indagação de quem traduz, cuja resposta muda ao longo do tempo de realização e interpretação e conduz também à questão da individualidade e autonomia de intérpretes e tradutores "infiéis" e cristãos de Toledo; ou da relação de confiança, controle e censura entre eles.

Quais as intenções e propósito e para quem se traduz tampouco têm respostas simples; as respostas óbvias e declaradas podem não ser as verdadeiras ou relevantes e também variam ao longo do tempo. Ou dos tempos: o da etapa de realização da tradução e o da sua interpretação a posteriori. Mesmo o que se traduz, que permitiria uma resposta numérica e objetiva, não tem uma resposta simples.

\section{Collège de traducteurs}

Embora o Collège ou Escola de Toledo não tenha existido em sua época com este nome, o termo collegium talvez lhe tivesse sido apropriado no sentido que se dava na época, de colegiado ou guilda, "corporação de pessoas reunidas para uma função comum". O termo Collège des Traducteurs só foi cunhado no começo

3 Tradução de Roger Maioli dos Santos. 
do século XIX, pelo orientalista francês Amable Jourdain. O certo é que não há prova documental de que tenha havido algo como um collège, scola, escola, escuela, school, Akademie (Feuchtwanger), Schule (Valentin Rose), como entendemos esses termos hoje, como instituições educacionais ou entidades jurídicas estáveis. Comentadores de hoje, como Santoyo (2006), não hesitam em chamar estas denominações de equívocos, mas não pareceria tão distante da realidade de sua época se considerarmos o uso medieval da palavra collegium. A própria designação foi criada fora da Espanha:

Foi Amable Jourdain quem, em 1819, primeiro cometeu o erro de falar de um "collège de traducteurs" naquela cidade espanhola, quando de fato os tradutores atribuídos à "Escola de Toledo" realizaram suas tarefas em lugares às vezes bem distantes de Toledo. O erro, no entanto, logo se espalhou por toda a Europa, e depois de Jourdain muitos outros eruditos do século XIX costumavam se referir à mesma "escola".

$[\ldots]$

Não, não existe tal escola de tradutores em Toledo, se a "escola" deve ser entendida em qualquer dos sentidos usuais da palavra. Já em 1942, Angel González Palencia (1942, p. 118) teve de admitir que "os poucos documentos que até agora foram encontrados não proporcionam uma base para afirmar-se a existência de um centro de traduções" (SANTOYO, 2006, p. 31, tradução nossa $)^{4}$

A chamada Escola de Toledo não foi, nem pretendeu ser em seu momento, uma escola no sentido de ser uma instituição com um quadro de professores ou lugar físico fixo e próprio. De fato, nem mesmo era chamada assim ou sequer tinha um nome específico; como é muito comum na História, só ganhou um nome e delimitação quando já não existia como tal. Além disso, engloba dois momentos e movimentos dessemelhantes.

4 It was Amable Jourdain who in 1819 first made the mistake of speaking of a "collège de traducteurs" in that Spanish town, when in fact the translators he ascribed to the "Toledo School" carried out their tasks in many other parts of the country, places sometimes quite far from Toledo. The error, however, soon spread all over Europe, and after Jourdain many other nineteenth-century scholars used to refer to the same "school." [...]

No, there was no such School of Translators at Toledo, if "school" is to be understood in any of the normal senses of the word. Already in 1942 Angel González Palencia $(1942,118)$ had to admit that "the very few documents which so far have been found do not provide a basis to assert the existence of such a centre of translations." 
Estabelecer uma delimitação territorial para a Escola parece fácil e objetivo. Os trabalhos na primeira etapa fossem realizados, sobretudo, na Catedral de Toledo; depois também em diversos outros prédios religiosos e, em seu segundo momento, sobretudo, em dependências privadas da nobreza, do rei ou do Estado. Os trabalhos de tradução também não se limitaram a Toledo e só na sua segunda encarnação estiveram sob direção ou intenção hispânica. De fato, a existência dessa guilda ou corpo de tradutores tampouco ajudou a formar, seja na cidade, seja na península, uma universidade ou centro de estudos autônomo. Os conhecimentos ali traduzidos e transmitidos floresceram em outros lugares; nomeadamente Paris, Bolonha e Oxford. Embora tivesse o apoio desde o início dos reis hispânicos, a escola foi promovida e dirigida nas suas primeiras décadas por arcebispos franceses. Se os intérpretes eram hispânicos, os tradutores eram, na sua prática totalidade, não hispânicos, francos $^{5}$ em sua maioria, como que emprestados de outras instituições europeias então nascentes, que buscavam conhecimentos para aplicar em seus lugares de origem. Não foi um fenômeno exclusivo daquela cidade e nem mesmo da Espanha. Toledo disputava a primazia com Sićlia e Nápoles e, mesmo na Espanha, não era a única cidade que traduzia. Tampouco, as campanhas ou colegiados de tradução eram uma novidade: o próprio rei muçulmano da taifa de Toledo, Al-Mamun ou Almamune (1043-1075), patrocinava traduções antes da conquista pelos cristãos, e Bagdá teve também a sua "escola de tradutores": "Mais ou menos se pode dizer o mesmo da célebre 'escola de tradutores de Bagdá' do século nono" (SANTOYO, 2006, p. 32, tradução nossa). ${ }^{6}$ Portanto, era bem semelhante em escopo e no seu caráter não formal à sua homóloga de Toledo.

O mais próximo de um corpo funcional próprio consistia de moçárabes, hebreus e muçulmanos almorávidas que interpretavam oralmente textos árabes para a lingua tholedana, latim vulgar, romance ou proto-espanhol, como se queira, do qual eram então transpostos para a escrita em latim eclesiástico pelos francos. Não havia o equivalente a tradutores profissionais ou de tempo integral. Os intérpretes

5 O gentilício medieval franco abarcava mais e não era o mesmo que hoje entendemos como francês. Como povo germânico, estão na base da formação da Alemanha e dos Países Baixos, além da França, a qual deram nome. No contexto da Hispânia contemporânea da Primeira Cruzada, época e lugar da primeira Escola de Toledo, o franco é um europeu ocidental não hispânico que hoje seriam franceses, alemães, ingleses, escoceses; mesmo os catalães eram considerados como francos pelos muçulmanos. O que nos interessa aqui é justamente não estarem integrados ao mundo peninsular, não eram espanhóis, judeus ou muçulmanos e esta não integração foi um elemento essencial nas traduções que auspiciaram. Os clérigos francos, sem conhecer e justo por não conhecer o árabe, podiam corrigir e adaptar a primeira versão oral proporcionada por judeus, mulçumanos e cristãos hispânicos.

6 More or less the same can be said of the famous ninth-century Baghdad "school of translators." 
do árabe eram bedéis, sábios e artistas moçárabes, hebreus, muçulmanos, frequentemente conversos e refugiados das guerras territoriais e religiosas. Os tradutores para o latim, na maioria, eram clérigos estrangeiros buscando conhecimentos para levá-los a suas pátrias. Não se fazia a tradução direta e sem interposição da oralidade, um método antieconômico que tinha suas razões de ser. Ernest Renan explica o sistema oral de tradução, enfatizando que era comum a outras "escolas" de tradução da época:

As relações da Europa com os muçulmanos ocorriam, de um lado, pela Espanha, e sobretudo por Toledo; do outro, pela Sicília e o reino de Nápoles. $\mathrm{O}$ trabalho dos tradutores era realizado nestes dois pontos com igual ardor e pelos mesmos procedimentos. Quase sempre um judeu, às vezes um muçulmano convertido, desbastava a obra e aplicava a palavra latina ou a palavra vulgar sobre a palavra árabe. Um clérigo presidia o trabalho, encargava-se do latim e dava seu nome à obra. Algumas vezes, no entanto, levava também o nome do secretário judeu, de onde decorre que uma mesma tradução seja frequentemente atribuída a personagens diferentes. Nos séculos XII e XIII, as traduções eram feitas sempre diretamente do árabe. Somente muito mais tarde, começou-se a traduzir os filósofos árabes sobre versões hebraicas. (RENAN, 1992, p. 146, tradução nossa). ${ }^{7}$

Faziam, portanto, um trabalho análogo ao dos copistas, que transcreviam o que se lhes ditava para a escrita, mas desta vez do que ouviam em sermo vulgaris ou lingua tholedana para o latim escrito escorreito. Seus métodos de trabalho se assemelhavam aos dos scriptoria e studii de produção de manuscritos.

\section{Culturas de tradução}

A Escola ou Escolas de Toledo e suas etapas e métodos parecem se encaixar razoavelmente no que Peter Burke chama, no prefácio de $A$ tradução cultural no

7 Las relaciones de la Europa con los musulmanes tenían lugar de un lado por España, y sobre todo por Toledo; del otro por Sicilia y el reino de Nápoles. El trabajo de los traductores se operaba en estos dos puntos con igual ardor y por los mismos procedimientos. Casi siempre un judío, s a menudo un musulmán convertido, desbastaba la obra y aplicaba la palabra latina o la palabra vulgar sobre la palabra árabe. Un clérigo presidia el trabajo, se encargaba del latín y daba su nombre a la obra. Algunas veces, sin embargo, llevaba también el nombre del secretario judío, de donde proviene el que una misma traducción sea frecuentemente atribuida a personajes diferentes. En los siglos XII y XIII, las traducciones se hadan siempre directamente del árabe. Sólo mucho más tarde se empezaron a traducir los filósofos árabes sobre versiones hebraicas. 
primórdios da Europa Moderna (HSIA \& BURKE, 2009), de "culturas de tradução" e seus regimes. Tendo partido de Amable, o mais célebre patrocinador, ainda no século XIX, da ideia de uma escola de tradutores foi Ernest Renan; a ideia foi posteriormente incorporada na Espanha por Menéndez-Pelayo. Para Renan, a iniciativa Escola de Toledo foi um evento revolucionário e essencial, cujos méritos atribui ao seu conterrâneo francês, o arcebispo Raimundo; Renan destaca também o hispânico Gundisalvo, e reduz Abu Bakr Muhammad ibn Dawud al-Zahiri ou João Avendeath a um subordinado do anterior:

A honra desta tentativa, que havia de ter uma influência tão decisiva sobre a sorte da Europa, corresponde a Raimundo, arcebispo de Toledo e grande chanceler de Castela de 1130 a 1150. Raimundo forma ao seu redor o colégio de tradutores, à cabeça do qual se encontra o arquidiácono Domingo Gundisalvo ou González Dominicus Gundisalvi. Vários judeus, dentre os quais o mais conhecido é João Avendeath, trabalhavam sob suas ordens. Este primeiro ensaio versou, principalmente, sobre Avicena. Gerardo de Cremona e Alfredo Morlay acrescentaram, alguns anos mais tarde, diversos tratados de Alkindi e de Alfarabi. Assim, desde a primeira metade do século XII, eram conhecidas dos latinos as mais importantes obras de filosofia árabe. (RENAN, 1992, p. 145, tradução nossa). ${ }^{8}$

Na verdade, a atividade de Gundisalvi ou Gundissalinus foi exercida sobretudo sob o auspício do sucessor de la Sauvetât, outro arcebispo francês, João de Castellmoron, após 1152, o que só confirma a primazia francesa na campanha de tradução de Toledo. O arcebispo antecessor de Raimundo de la Sauvetât também era francês, Bernardo de Cluny, e o arcebispado continuaria francês (ou franco) até quase o final daquele século. O importante é que a partir de Ernest Renan é que a Escola de Toledo recobra importância histórica e se torna um mito ou narrativa da história da tradução. A tendência a sobrevalorizar as traduções de filosofia (um quinto ou menos) sobre as outras, também parece partir dele.

Como dito, além da precursora "Escola de Bagdá", havia uma concorrente contemporânea na Sicília da corte normanda, com similaridades de contexto e

8 El honor de esta tentativa, que había de tener tan decisivo influjo en la suerte de Europa, corresponde a Raimundo, arzobispo de Toledo y gran canciller de Castilla de 1130 a 1150 . Raimundo forma en torno suyo un colegio de traductores, a la cabeza del cual se halla el arcediano Domingo Gundisalvo o González Dominicus Oundisalvi. Varios judíos, entre los que el más conocido es Juan Avendeath, trabajaban bajo sus órdenes. Este primer ensayo versó principalmente sobre Avicena. Gerardo de Cremona y Alfredo Morlay añadieron, algunos años más tarde, diferentes tratados de Alkindi y de Alfarabi. Así, desde la primera mitad del siglo XII, eran conocidas de los latinos las más importantes obras de filosofía árabe. 
circunstância e até um grande tradutor, Gerardo de Cremona, que atuou em ambas. Elas foram os protótipos de outros surtos ou campanhas ou culturas de tradução posteriores pela Europa, como, na própria Espanha, na corte de Carlos V, no século XVI; ou os patrocínios às traduções do rei Gustavo Adolfo, na Suécia, e do czar Pedro, o Grande, na Rússia, nos séculos XVII e XVIII, respectivamente; todos com o objetivo declarado de modernizar e europeizar seus países.

A exemplo do papel que, ao longo dos séculos, refugiados huguenotes, italianos protestantes, hebreus da diáspora exerceram - aquele de mediadores culturais, desempenhado por moçárabes, mouros e, outra vez, hebreus na Toledo medieval. Outra vez, Ernest Renan vai mencionar a importância dessa intermediação. Embora não tenha um viés negativo, não deixa de ser uma preconcepção:

Os judeus cumpriam em suas relações um papel essencial, que não foi levado em conta o suficiente na história da civilização. Sua atividade comercial e sua facilidade para aprender as línguas, tornavam-nos intermediários naturais entre os cristãos e os muçulmanos (RENAN, 1992, p. 146, tradução nossa). ${ }^{9}$

Também a Companhia de Jesus, desta vez por todo mundo, Américas e Ásia, sobretudo, quis suprir nos séculos posteriores o papel que o arcebispado franco de Toledo havia exercido, em torno da Catedral, no primeiro século da Escola, levando conscienciosamente os conhecimentos do mundo para a Europa e, sobretudo, sua visão religiosa da Europa para o mundo (HSIA e BURKE, 2009).

Entre as culturas envolvidas, o próprio conceito do que seria uma tradução era diverso e conflitante. As traduções medievais europeias tendiam a ser maciçamente literais e sacralizantes do original, enquanto as traduções hebraicas e muçulmanas tendiam a parafrasear e explicar. Nessas tradições, mesmo hoje, considera-se que não há propriamente traduções de textos sacros, mas comentários.

[...] Haskins estava ciente do fato de que tais traduções eram quase universalmente uma característica essencial da vida intelectual árabe na Europa da época (tanto na Sicília quanto em Espanha); que muitas das "traduções" mais influentes não eram de fato traduções do grego, mas traduções de comentários filosóficos árabes sobre Aristóteles, que durante alguns séculos tinha sido um dos luminares filosóficos da tradição árabe; e que a

9 Los judíos cumplían en sus relaciones un papel esencial, que no se ha tenido en cuenta lo suficiente en la historia de la civilización. Su actividad comercial y su facilidad para aprender las lenguas, hacían de ellos los intermediarios naturales entre los cristianos y los musulmanes. 
propagação e recepção de tais textos eram pelo menos em certa medida explicáveis apenas em termos de uma penetração e conhecimento mais profundos da vida intelectual árabe na Europa e de seu alentado prestígio, muito maior do que o que havia tido anteriormente. (MENOCAL, 2004, p. 10 , tradução nossa). ${ }^{10}$

Isso abre as portas para uma intermediação do mundo hebraico-islâmico da tradição grega. No conto "La busca de Averroes" (BORGES, 1974), Jorge Luis Borges narrará a busca de Averróis de equivalências nocionais ou correspondências para os conceitos da Antiguidade greco-latina no árabe. Esta busca de entendimento de noções e conceitos que não existiam entre os muçulmanos será útil para a transposição dessas noções que também não existiam mais na Europa.

Averróis abre-nos um campo intelectual: o da transposição da tradução. Ele transpõe Aristóteles para o quadro da cultura andaluza sem qualquer servilismo; fornece equivalentes nocionais para diferentes conceitos do Estaginta; propõe uma filosofia da tradução em que os conceitos básicos de uma cultura encontram seus correspondentes em outra. O Corão? Uma narrativa homérica. A mesquita? Um ginásio. $\mathrm{O}$ imã? O legislador grego. A interpretação da Lei? O silogismo. Esse campo intelectual - mais pacífico do que o do consenso - salvaguarda, com a prática filosófica, a pluralidade das formas de vida e de pensamento. (BENMAKHLOUF, 2006, p. 223). ${ }^{11}$

No romance de Feuchtwanger, citado acima, uma cena ilustra ficcionalmente tanto o tipo de tradução cultural ou nocional da época quanto o papel da oralidade e sua imediatez no método de tradução da época:

Entre os adágios na parede estava aquele antigo árabe que o tio Musa tanto amava: "Uma paz leve como a pluma é melhor do que uma vitória com peso de ferro". Raquel leu o adágio para ele; as estranhas palavras vieram plenas, sombrias e elevadas de seus lábios juvenis. Como ele não entendeu,

10 Haskins was aware of the fact that such translations were almost universally an essential feature of Arabic intellectual life in Europe at the time (both in Sicily and Spain); that many of the most influential "translations" were not at all translations from the Greek as such, but rather translations of Arabic philosophical commentaries on Aristotle, who for some centuries had been one of the philosophical luminaries in the Arabic tradition; and that the propagation and reception of such texts was at least in some measure explicable only in terms of a deeper penetration and knowledge of Arabic intellectual life in Europe, and of its far greater prestige, than had previously been adduced.

11 Tradução de Guilherme João de Freitas Teixeira. 
ela traduziu para o latim vulgar: "Uma onça de paz vale mais do que uma tonelada de vitória”. - Isso é bobagem - disse Alfonso, imperiosamente. - Isso vale para camponeses e burgueses, não para cavaleiros. Porém, não querendo ofender Raquel, disse: "Isso pode ser adequado na boca de uma dama”. (FEUCHTWANGER, 1983, p. 290, tradução nossa). ${ }^{12}$

A hebreia do romance precisou "se traduzir", ou seja, se colocar no lugar do Outro e interpretou o que era uma metáfora ao uso semítico, que contrastava suavidade e dureza, com uma metáfora em termos de peso, apropriada para um guerreiro cristão. O Alfonso VII ficcional, sucessivamente, não entendeu, entendeu em seus próprios termos e, finalmente, colocou-se no lugar do outro para entender como o outro poderia entender, ainda que só como concessão tolerante à sua interlocutora.

Se a primeira fase da Escola foi eclesiástica, coletivista e francesa, na segunda, mais curta e individualista, a direção era política, pelo rei Alfonso X, o Sábio. As traduções se faziam direto do árabe, do grego, do hebraico e, agora também, do latim, para o castelhano, herdeiro do romance hispânico, sem a interposição da oralidade. No processo, o dialeto castelhano ganhava foros de língua nacional, como o espanhol.

As traduções eram feitas por eruditos de vários credos, predominantemente hispânicos, e eram coordenadas pelo rei que se fazia chamar de Imperador das Duas Fés. Serviam aos interesses políticos e intelectuais locais, pessoais e políticos do rei Alfonso X, ele próprio um historiador notável em castelhano, autor das Crónicas Generales que compendiam a história da Espanha (e compendiam os amores de seu avô com a Judia de Toledo). Significativamente, fez que o espanhol fosse adotado como língua do seu reinado em detrimento do latim. Curiosamente, também é lembrado como notável poeta em galego-português, a língua de sua mãe.

O questionar e discutir os métodos, sistemas, regimes, habitus ou culturas de tradução é bastante relevante, porque revela os condicionantes que levaram à escolha desses procedimentos e não de outros. Além de ter suas repercussões teóricas e práticas que ainda nos afetam hoje.

12 Unter den Sprüchen an der Wand war jener uralte arabische, den Onkel Musa so liebte: "Ein Federgewicht Frieden ist besser als ein Eisengewicht Sieg." Sie las ihm den Spruch; voll, dunkel und groß kamen die seltsamen Worte von ihren kindlichen Lippen. Da er nicht verstand, übersetzte sie ins geläufigere Latein: "Eine Unze Friede ist mehr wert als eine Tonne Sieg." "Das ist Unsinn", erklärte Alfonso herrisch. "Das ist was für Bauern und Bürger, nicht für Ritter.” Da er aber Raquel nicht verletzen wollte, begütigte er: "Im Munde einer Dame mag es angehen." 
O que pode ser feito aqui é situar esses textos em seu contexto cultural, incluindo os sistemas ou "regimes" de tradução prevalentes nesse período - em outras palavras, às regras, normas 'ou convenções que governavam sua prática, tantos os fins - (ou “estratégias") como' os meios (as “táticas" ou "poéticas") (HSIA e BURKE, 2009, p. 17) ${ }^{13}$

Os tradutores ou intérpretes orais do árabe para o romance hispânico eram predominantemente moçárabes, cristãos de cultura árabe, e algumas vezes hebreus ou mouros convertidos. Curiosamente, segue-se aqui a prática islâmica de relegar a tradução a convertidos e renegados, segundo Peter Burke. No entanto, os tradutores finais para o latim escrito eram sempre intelectuais cristãos confiáveis, quase sempre de outras partes da Europa ou educados fora da Península Ibérica. Garantia-se assim o caráter pan-europeu, mais que ibérico, da empreitada.

A etapa obrigatória de interpretação em voz alta do texto árabe ou hebraico em romance hispânico é um método antieconômico, no sentido de mais cansativo e caro, senão no sentido econômico, no sentido do uso da mão de obra, mas atende a várias determinantes sócio-religiosas, linguísticas e até jurídicas (PALENCIA, Los mozárabes de Toledo en los siglos XII y XII, 1930). De certa forma, as exigências de fidedignidade sobrepunham-se às necessidades práticas de fidelidade ao original, com a introdução, neste caso literal, de ruídos de comunicação. Sobretudo, garantia-se assim o controle religioso sobre o produto final.

\section{Toledo, Babel}

Toledo já era um importante centro de aprendizagem e tradução quando foi conquistada por hispânicos e europeus do Norte. Segundo Gonzáles Palencia e outros autores, Toledo era simplesmente uma cidade de língua e cultura arabizadas e mesmo os cristãos locais eram bilíngues. Tampouco os cristãos conquistadores do norte da Península desconheciam o árabe e, segundo, outra vez, Gonzáles Palencia, logo se arabizaram culturalmente. Palencia constata que a corte do conquistador da cidade não se distinguia em moda, língua e costumes de uma corte muçulmana e o herdeiro do rei era filho de uma rainha ou concubina árabe convertida. Por outro lado, os numerosos cavaleiros e clérigos que atravessaram os Pireneus logo criaram um bairro próprio e separado cultural e linguisticamente, o arcebispado

13 Tradução de Roger Maioli dos Santos. 
toledano seria, pelos primeiros cem anos após a conquista, uma possessão franca ou francesa. Isso terá, claro, consequências na Escola de Toledo.

Para a historiadora cubana María Rosa Menocal, o que ocorreu de mais extraordinário em Toledo foi um despertar do conquistador diante da cultura do conquistado.

A conquista de Toledo abriu aos europeus as portas para o que anteriormente estava restrito aos andaluzes. $\mathrm{O}$ grande aumento do fluxo de traduções dessa cidade, cujo nome se tornaria sinônimo de arte e ciência da tradução de textos árabes, representava um tipo diferente de ameaça e representava um tipo diferente de maldade. Instilou os medos e preocupações que o conhecimento filosófico secular e as ciências sempre invocaram em instituições religiosas, fosse qual fosse o credo. (MENOCAL, 2004, p. 41).

E esta é uma ameaça que vai além da religião e da disputa por terreno contra o Islã; havia ali uma Kulturkampf, como a que Bismarck depois travaria no século XIX contra a França e o catolicismo para consolidar a unificação da Alemanha. Nos dois casos, a derrota cultural teria inviabilizado quaisquer conquistas territoriais e políticas. Ainda segundo Menocal,

devemos prontamente ser capazes de perceber o poder sedutor do milieu cultural árabe para a comunidade intelectual e artística europeia - apesar da importância da ameaça territorial que o Islã representava para a Europa. A verdadeira ameaça, de fato, era cultural, e essa ameaça tinha pouco a ver com o islamismo ou a conquista territorial (MENOCAL, 2004, p. 47, tradução nossa). ${ }^{14}$

Portanto, a tarefa de tradução era tanto uma busca de aproximação quanto uma atividade de contenção contra o aluvião cultural do "Oriente". Como afirma Burke, ainda em A tradução cultural (2009), uma sociedade procura na outra cultura aquilo que lhe falta e de que precisa, mas também aquilo que reconhece e a deixa confortável; para isso, precisa modificar e subverter o importado. Esta valorização da tradução não afeta o público local cristão, que não precisava de traduções para aceder à cultura árabe. De fato, a elite política tampouco tinha condições

14 we should be readily able to perceive the seductive power of the Arabic cultural milieu for the European intellectual and artistic community-despite the importance of the territorial threat that Islam posed for Europe. The real threat, indeed, was a cultural one, and this threat had little to do with either Islam or territorial conquest.. 
de traduzir das línguas semíticas, não por desconhecer o árabe, que usavam no cotidiano, mas por falta de domínio do latim eclesiástico que era a língua franca europeia. Portanto, o empreendimento da transmissão do conhecimento em árabe para o Ocidente foi maiormente transpirenaico, realizado por intelectuais de fora da Península ou por algum raro intelectual hispânico educado na França, como foi Gundissalinus; com a colaboração anônima de eruditos moçárabes e hebraicos, e sem participação historicamente registrada de outros clérigos locais. Alguns dos seus principais tradutores, para exemplificar, seriam Herman Alemanus, alemão da Caríntia; Gerardo de Cremona, italiano, que também atuou na Escola de Tradutores da Sicília; Daniel de Morlay, anglo-normando; Alexander Neckham, inglês, e Miguel Scoto, escocês ou inglês.

\section{Conclusão}

No capítulo nono do Quixote, séculos depois, Miguel de Cervantes parodiará o estranho processo, quando apresenta seu fictício tradutor: um suposto intérprete mourisco anônimo e solícito, um provável mendigo, que na narrativa será quem primeiro verterá o suposto original árabe de Cide Hamete Benengeli do romance para um espanhol oral, para que Cervantes o ponha no papel em boa língua cristã.

Foi em 1160 que o filósofo hebreu Abraham ibn Daud ou ben David ou Avendeuth ofereceu seus serviços aos líderes da cidade para traduzir Avicena (Ibn Sinnā), o que foi aceito, com condições. Ibn Daud alegadamente não tinha domínio suficiente do latim para traduzir sozinho e associou-se ao arquidiácono Dominicus Gundissalinus (Domingo Gundisalvi ou Gundisalvo). No prólogo, de Avendeuth, o seu método de tradução é explicitado: "Assim, traduzimos o livro do árabe, comigo assumindo a liderança e representando cada palavra na língua vernácula, e o arquidiácono Dominicus transpondo as palavras para o latim" (BURNETT', 2001, p. 252).

Embora Avendeuth se apresente nesse prólogo como o cabeça da tradução, com o cristão Dominicus Gundissalinus tratado com familiaridade pelo prenome, como auxiliar, o fato é que o sábio hebreu não reaparece em outras traduções conhecidas. Enquanto Dominicus Gundissalinus se tornará um dos tradutores mais prolíficos, com outros sábios mulçumanos e hebreus, a partir daqui anônimos, ocupando o posto de Avendeuth.

A descrição assemelha-se notavelmente àquela de uma oficina de cópia de manuscritos, com interpretação em voz alta para que outros escrevessem, mas também na aplicação figurada da palavra latina sobre a árabe, como um palimp- 
sesto, um processo cumulativo, mas também destrutivo ou ocultador do que fica por baixo.

Burnett faz uma descrição mais simples, na mesma linha:

que um moçárabe ou judeu, que não era proficiente em latim, fez uma tradução intermediária de um texto para o vernáculo (seja o árabe coloquial de Toledo ou o dialeto românico local), que um clérigo educado no latim transpunha para um bom latim (BURNET'T, 2001, p. 252, tradução nossa) ${ }^{15}$

Este processo parece bastante exaustivo, com grande dispêndio de tempo e de pessoal qualificado, e depende da disponibilidade de um grande número de profissionais. Neste caso, o enorme número de sábios hebreus e mouriscos refugiados e disponíveis, e de intelectuais europeus ávidos dos conhecimentos na língua árabe. Havia também outros condicionantes que justificam a escolha desses procedimentos e que não eram exclusivos de Toledo, visto que o método era empregado em outras partes na época.

Havia, primeiro, a questão consuetudinária da forma de leitura. Simplesmente, não era comum a leitura silenciosa, mesmo privada. Ler praticamente implicava falar ou murmurar o texto. O que para nós seria um vício de leitura, ou um esforço a mais, era, para o homem medieval, apenas o seu modo habitual de ler. Agostinho de Hipona (santo Agostinho) demonstrou surpresa quando encontrou o bispo Ambrósio de Milão lendo introspectivamente, o que lhe pareceu extraordinário e inquietante (NUNES, p. 161). Precisou especular sobre as razões de Ambrósio e aceitar que, fosse qual fosse, deveria ser boa:

Se mesmo a leitura individual era falada, a leitura coletiva dos copistas medievais era mais ainda. Os scriptoria de reprodução de manuscritos eram ambientes ruidosos. Um orador lia em voz alta o manuscrito a ser copiado e os copistas passavam o que ouviam para o pergaminho.

A asserção comum de que os sábios hebreus não podiam traduzir diretamente do árabe para o latim é discutível. De fato, era motivo de reprimenda religiosa entre os hebreus da época que eles estudassem mais o latim cristão do que o hebraico:

15 that a Mozarab or Jew, who was not proficient in Latin, made an intermediate translation of a text into the vernacular language (whether the colloquial Arabic of Toledo or the local Romance dialect), which a cleric educated in the Latin schools transferred into good Latin. 
O estudo da língua latina estava nesta época muito estendido entre os judeus. Em 1280, Salomão-ben-Adereth, de Barcelona, escreveu uma carta aos judeus das sinagogas da Provença para repreendê-los por estudar a língua latina em detrimento da lei (PASINI, I, págs. 61-62 apud RENAN, 1992, p. 146 , tradução nossa) ${ }^{16}$

Não seria, no entanto, viável deixar na mão de tradutores infiéis, aqui no sentido religioso, a tradução de textos filosóficos e religiosos, sob o risco de serem também infiéis no sentido linguístico.

O papel da oralidade nessas traduções ajuda a explicar a inexistência da tradução literária lírica na Escola. Isto é determinado, primeiramente, pela questão de para quem a tradução é feita; a população local consumia e mesmo produzia poesia popular, quase sempre amorosa, diretamente em árabe, e a poesia árabe não interessava aos clérigos de língua latina. E não porque fossem especialmente castos, mas porque tinham outras tradições de poesia erótica, com a dos Carmina Burana.

Mais tarde, coincidindo com segunda etapa da Escola, relacionada, haverá um tipo de "tradução de procedimentos". A chamada Canção de Amigo galego-portuguesa será uma derivação da poesia amorosa moçárabe, em geral composta em língua românica com refrão em árabe ou hebraico. Como fórmula e tema, mudará muito pouco; onde surge o habib no refrão árabe, se usa amigo, significando amante. Além da dificuldade técnica e literária inerente da tradução de versos de outra língua, religião e cultura, está o fato de que tais traduções, mesmo se existiram, não foram postas no papel ou eram traduções anônimas, de todo modo, não preservadas.

O que não quer dizer que não tenha havido influência literária indireta. De todo modo, no começo da literatura castelhana são comuns as adaptações da sabedoria oriental sob a forma de contos de fundo moral, sem que se chame isso de tradução. Mesmo Boccaccio no Decamerão aproveitou temas árabes em alguns enredos. $\mathrm{O}$ fato é que a Escola de Toledo não é associada comumente à tradução de literatura. Cálculo, cosmogonia e medicina concentravam $70 \%$ das traduções, bem acima da filosofia, com cerca de $20 \%$ das traduções, embora sejam as mais lembradas atualmente, com a religião muito atrás. No entanto, o arabista espanhol

16 El estudio de la lengua latina estaba en esta época muy extendido entre los judíos. En 1280, Salomónben-Adereth, de Barcelona, escribió una carta a los judíos de las sinagogas de Provenza para reprenderles por estudiar la lengua Latina en, detrimento de la ley. 
Asín Palacios levantou hipóteses sobre a influência da mística árabe sobre Dante Alighieri na criação da Commedia (MENOCAL, 2004). María Rosa Menocal levanta a questão para logo questionar a extensão dessa influência: "Está bem sugerir que aqueles poetas cuja dedicação à fé seja suspeita possam ter encontrado algo atraente e imitável no mundo dos muçulmanos. Mas Dante?” (MENOCAL, 2004, p. 122 , tradução nossa). ${ }^{17}$

Não é possível esquecer que Avendauth, ${ }^{18}$ quem primeiro propôs o método da tradução intermediada oralmente, era um hebreu, portanto, de uma cultura acostumada a esta corporeidade verbal da palavra escrita, mas isto estava longe de ser algo raro ou estranho entre muçulmanos e cristãos.

Hsia e Burke sugerem que, do ponto de vista do historiador cultural, "a tradução revela [...] o que uma cultura acha interessante em outra" (HSIA e BURKE, 2009, p. 26). Mas este interesse atua segundo dois princípios opostos, só aparentemente, opostos.

O primeiro, é o de que a tradução serve para "preencher lacunas na cultura hospedeira” (HSIA \& BURKE, 2009). O segundo é "o princípio da confirmação, segundo o qual, pessoas de uma cultura traduzem obras que sustentam ideias, premissas ou preconceitos já presentes nela. (HSIA \& BURKE, 2009).

Hsia e Burke apresentam como um corolário deste segundo princípio o que poderia ser de fato um terceiro princípio unificador. Ou, em termos dialéticos, uma síntese para a tese e antítese que os dois princípios acima representam: "Caso não sustentem ideias desse tipo, as traduções são modificadas [grifo nosso], direta ou indiretamente" (HSIA \& BURKE, 2009, p. 27). Segundo Menocal:

Por outro lado, houve uma europeização, uma adaptação e absorção dentro deste paradigma, do corpus de informações que revelam essas "traduções" do árabe, particularmente nos séculos XI e XII, que contribuíram decisivamente para o renascimento intelectual da Europa daquela época (MENOCAL, 2004, pp. 9-10). ${ }^{19}$

17 It is all well and good to suggest that poets of suspect dedication to the faith might have found something appealing and imitable in the world of Muslims. But Dante?

18 Conforme o autor e a época, o tradutor judeu Abraham ibn Daud é também chamado ben David ou Avendeuth. Renan adota a grafia Avendauth.

19 On the one hand, there has been a Europeanization, an adaptation and absorption into this paradigm, of the body of information that reveals that Arabic "translations", particularly in the eleventh and twelfth centuries, contributed decisively to the intellectual revival of Europe at that time. 
De todo modo, e ao contrário do lugar comum das obras de referência, a tradução não começou por obras de filosofia e religião, mas por temas mais técnicos e pragmáticos:

Em geral, as primeiras obras traduzidas do árabe não foram obras filosóficas. A medicina, as matemáticas, a astronomia, haviam atiçado a curiosidade de Constantino, o Africano, de Gerberto, de Abelardo de Bath, de Platão de Tívoli, antes de que se sonhasse em pedir ensinamentos filosóficos a infiéis como Alfarabi e Avicena. (RENAN, 1992, p. 145, tradução nossa) ${ }^{20}$

Em termos de táticas de tradução, a intermediação da oralidade acaba se revelando um método propício para este ajuste entre o que se precisa e o que se deseja entre duas culturas.

As duas etapas da que foi chamada Escola de Tradutores de Toledo são tão diferentes, até opostas, que seria mais preciso chamá-las respectivamente Escola Eclesiástica ou Franca e Escola Alfonsina ou Castelhana respectivamente, em vez de colocá-las sob um só chapéu. Sem que isso implique que alguma delas tenha sido propriamente uma escola, antes movimentos ou missões coletivas ou colaborativas. A primeira foi criada para atender a interesses do norte da Europa de aquisição de conhecimentos orientais e clássicos, realizada por clérigos que depois levaram seus conhecimentos no retorno a seus países de origem. Dependeu do afluxo de sábios hebreus e muçulmanos, alguns convertidos, que chegaram como arquitetos, artistas, intelectuais e se tornaram em Toledo tradutores anônimos. Traduzia-se do árabe, depois também do hebraico, para o latim eclesiástico. Esses clérigos exerciam a função múltipla de intermediários e censores do que a cultura dos infiéis podia proporcionar à nova civilização pan-europeia.

Captavam o necessário, colhiam o que queriam e modificavam o que podiam.

A Escola Alfonsina, pelo contrário, era voltada para a Espanha nascente, era feita por hispânicos de vários credos e etnias, e do árabe, hebraico, grego e, agora também, do latim, para o castelhano, alçado à condição de língua nacional. O regime de trabalho era mais colaborativo, com a participação direta do rei como revisor e censor, do que coletivo. Embora ainda se ditassem textos, isto era incidental, uma comodidade, e não algo inerente ao modo de traduzir.

20 En general, las primeras obras traducidas del árabe no fueron obras filosóficas. La medicina, las matemáticas, la astronomía, habían tentado la curiosidad de Constantino el Africano, de Gerberto, de Abelardo de Bath, de Platón de Tívoli, antes de que se soñase en pedir enseñanzas filosóficas a infieles como Alfarabi y Avicena. 
Sobretudo, era um projeto político nacional. Alfonso X preparava-se para unificar a Espanha sob os reinos de Leão e Castela e preparava o castelhano para ser o veículo linguístico dessa unificação. Um projeto bem-sucedido no longo prazo e que desembocará na Gramática de Nebrija (Nebrija, 1492) e terá repercussões na conquista das Américas e até hoje.

Existe hoje como um protótipo, modelo, miragem de uma cultura ou culturas da tradução, na acepção de Burke que chegou até nós, a partir da História, mas ultrapassando-a. A relação entre os intelectuais e tradutores europeus naquele primeiro momento em Toledo criou o modelo do que seria o comportamento de apropriação cultural posterior de outras culturas e línguas pela Europa. Se por um lado, reconheciam o esplendor, validade e necessidade das culturas e línguas semíticas e seu papel preservador, mediador e transformador da cultura clássica europeia, por outro, mantinham a apropriação destas culturas estritamente controlada por agentes confiáveis, com precauções e com o apagamento das contribuições individuais dos povos admirados, mas colonizados. De fato, quase todos os brilhantes contribuidores não clérigos das traduções foram tornados anônimos ou ignorados posteriormente em nome de seus coordenadores (e censores) clérigos.

\section{Referências bibliográficas}

ALFONSO. Primera crónica general: estoria de España que mandó componer Alfonso El Sabio y se continuaba bajo Sancho IV en 1289.

ALIGHIERI, D. Da linguagem vulgar. E-books Brasil, 1999.

BASTIN, G. L., \& BANDIA, P. F. Charting the Future of Translation History. Ottawa: University of Ottawa Press, 2006.

BENMAKHLOUf, A. Averróis. (G. J. Teixeira, Trad.). São Paulo: Estação Liberdade, 2006.

BERMANN, S., \& WOOD, M. (Eds.). Nation, language, and the ethics of translation. Princeton, N. J: Princeton University Press, 2005.

BORGES, J. L. Obras completas. Buenos Aires: Emecé, 1974.

BURNETT, C. The Coherence of the Arabic-Latin Translation Program in Toledo in the Twelfth Century. Science in Context, 14, pp. 249-288 doi:10.1017/S0269889701000096. In: C. Burnett (2001).

FEUCHTWANGER, L. Die Jüdin von Toledo. Frankfurt am Main: Roman-Fischer Taschenbuch Verlag, 1983.

FOLENA, G. Volgarizzare e tradurre (Vol. Volume 605 de Piccola Biblioteca Einaudi). Turim, Itália: G. Einaudi, 1994. 
HIPONA, A. d. The Confessions of Saint Augustine. San Diego, Ca: ICON Group International, 2005.

HSIA, R. P.-c., \& BURKE, P. A tradução cultural nos primórdios da Europa moderna. (R. M. Santos, Trad.). São Paulo: UNESP, 2009.

HUNG, E. (Ed.). Translation and cultural change: studies in history, norms, and image projection. Amsterdam: Philadelphia: John Benjamins Pub. Co, 2005.

JOURDAIN, A. Recherches critiques sur l'âge et l'origine des traductions latines d'Aristote. Paris: Paris Joubert, 1843.

KALTNER, J., \& MCKENZIE, S. L. (Eds.). Beyond Babel: a handbook for biblical Hebrew and related languages. Atlanta: Society of Biblical Literature, 2002.

KERMODE, L. E. Aliens and Englishness in Elizabethan Drama. Cambridge: Cambridge University Press, 2009.

LEWIS, B. From Babel to dragomans: interpreting the Middle East. New York: Oxford University Press, 2004.

MENOCAL, M. R. The Arabic Role in Medieval Literary History. University of Pennsylvania Press, 2004.

NARVÁEZ, D., \& Lapsley, D. K. (Eds.). Personality, identity, and character: explorations in moral psychology. New, York, Cambridge: Cambridge University Press, 2009.

NEBRIJA, A. d. Gramática de la lengua Castellana. Salamanca, 1492.

NUNES, C. O. Leitura na Idade Média: a ruptura com a oralidae. Biblos, Rio Grande, 21: 0-000, 2007.

PALENCIA, Á. G. Los mozárabes de Toledo en los siglos XII y XII (Vol. Volume preliminar). Madri: Institudo de Valencia de Don Juan, 1930.

PALENCIA, Á. G. Los mozárabes de Toledo en los siglos XII y XII (Vol. Volume II). Madri: Instituto de Valencia de Don Juan, 1930.

PALENCIA, Á. G. Los mozárabes de Toledo en los siglos XII y XII (Vol. III). Madri: Instituto de Valencia de Don Juan, 1930.

PICK, L. K. Conflict and Coexistence: Archbishop Rodrigo and the Muslims and Jews of Medieval Spain. Michigan: University of Michigan, 2004.

RENAN, E. Averroes y el Averroísmo. Madrid: Hiperion, 1992.

SANTOYO, J.-C. Blank Spaces in the History of Translation. In: G. L. Bastin, \& P. F. Bandia, Charting the Future of Translation History (pp. 11-43). Ottawa: University of Ottawa Press, 2006.

SCHOLEM, G. G. O nome de Deus: A teoria da linguagem e outros estudos de cabala e mistica: judáica II. (J. Guinsburg, \& R. J. Solon, Trads.). São Paulo: Perspecitiva, 1987.

SPOLSKY, B. The languages of the Jews: a sociolinguistic history. New York: Cambridge University Press, 2014. 